\title{
Are Experts (News)Worthy? Balance, Conflict and Mass Media Coverage of Expert Consensus ${ }^{1}$
}

\author{
Eric Merkley \\ Postdoctoral Fellow \\ Munk School of Global Affairs \& Public Policy \\ University of Toronto \\ eric.merkley@utoronto.ca \\ ****Forthcoming in Political Communication****
}

\begin{abstract}
Overlooked in analyses of why the public often rejects expert consensus is the role of the news media. News coverage of expert consensus on general matters of policy is likely limited as a result of journalists' emphasis in news production on novelty and drama at the expense of thematic context. News content is also biased towards balance and conflict, which may dilute the persuasiveness of expert consensus. This study presents an automated and manual analysis of over 280,000 news stories on ten issues where there are important elements of agreement among scientists or economists. The analyses show that news content typically emphasizes arguments aligned with positions of expert consensus, rather than providing balance, and only occasionally cites contrarian experts. More troubling is that expert messages related to important areas of agreement are infrequent in news content, and cues signaling the existence of consensus are rarer still.
\end{abstract}

\footnotetext{
${ }^{1}$ Thanks to my dissertation committee, Paul Quirk, Richard Johnston, and Fred Cutler, as well as my external examiner John Bullock for the useful comments and suggestions. Also grateful for useful feedback from Dominik Stecula and Frédéric Bastien. Thanks as well to Kala Bryson for her exceptional research assistance. Data and replication materials are available with the Open Science Foundation (https://osf.io/rks8b/). My doctoral research was funded by the Social Sciences and Humanities Research Council of Canada [grant \#767-2015-2504].
} 
A sizable segment of the American public continues to hold beliefs opposed to the mainstream scientific consensus that climate change is happening and human-caused. However, there are many other issues where the public disputes important areas of expert consensus (Pew Research, 2015; Sapienza \& Zingales, 2013). A growing experimental literature has shown that experts, when in consensus, can be persuasive to citizens (Johnston \& Ballard, 2016; Lewandowsky et al. 2012; van der Linden et al., 2016), but processes of motivated reasoning often prevent citizens' assimilation of counter attitudinal signals from experts on some highly charged issues (Johnston \& Ballard, 2016; Kahan et al., 2012; Lewandowsky \& Oberauer, 2016).

The fault for sharply diverging opinions between experts and the public may not entirely rest with citizens, however. Scholars must also be attentive to the political information environment the information space used by citizens to learn about political issues of which the news media is a critical part. There are grounds to suspect that journalists may by ill-suited to providing information about expert consensus over the course of covering the news. They have incentive to write stories focused on events and controversy rather than on the structural issues that set their context (Bennett, 2007; Iyengar, 1991) such as the existence of expert consensus on important questions. Further, the citation of contrarian experts in an effort to maintain a journalistic norm of balance may instil confusion among news consumers about the state of expert opinion on areas of consensus (Boykoff \& Boykoff, 2004; Koehler, 2016; Zehr, 2000).

Unfortunately, we know little about the prevalence of information on expert consensus or the ways in which such consensus is typically presented in the American news media across a wide range of issues. This study presents an automated and manual content analysis of over 280,000 articles and transcripts on ten issues where there is important agreement among scientists or economists. I construct dictionaries to generate automated counts of references to experts in such content and use supervised machine learning to identify articles with substantive content relevant to a particular area of consensus. I manually code a stratified sample of over 3,000 of these news stories to estimate the frequency with which experts are featured in content to discuss a point of consensus, how often clear cues are used to signal to readers the existence of consensus on a particular question, and how readily journalists provide balance to expert sources by either citing polarizing political opponents or contrarian experts, the latter thereby creating false balance.

The results suggest that journalists generally craft news content that emphasize arguments aligned with expert consensus positions rather than provide strictly balanced coverage. And, importantly, they do not often provide such balance to the perspective of the expert community by 
citing contrarian experts. More problematic is the tendency of journalists to situate messages from experts amidst claims and counterclaims by polarizing political actors - even on low salience issues which may prime citizens to resist messages signaling expert agreement.

The most troubling finding presented below, however, is that messages from experts relevant to important areas of consensus are not common in media content even when such content is directly relevant to that consensus. Clear cues signaling the existence of agreement or consensus among experts are rarer still. The news media does a poor job of informing citizens of expert consensus where it exists and when it is relevant to a news story.

\section{Media bias and the presentation of expert opinion}

There are reasons to expect that experts have gained prominence in the news media due to changes that have been occurring in society and in the news production process. Journalists now produce the news, rather than simply report the news. They need to avoid the appearance of bias when casting an interpretive lens to a story, and so use experts - with their appearance of impartial, factual knowledge - for "compensatory legitimation" (Albæk, 2011). Journalists also require experts to make sense of the world, especially given the extraordinary pressures of the 24-hour and now instantaneous news cycle that prevent them from engaging in their own research. They "depend on expert 'sparring partners' to develop a story and give it sufficient depth and breadth" (Albæk, 2011: 338). As a result, there is some evidence - at least in the Danish context - that university experts have seen a sustained increase in news coverage (Albæk et al., 2003). Unfortunately, empirical research on this question has been limited in the United States and elsewhere.

It is debatable whether this trend is normatively positive. Experts can be cited in news coverage to discuss their own research or the research of other scholars in closely related fields. But they may also be used to discuss topics unrelated to their fields of expertise. Albæk and his colleagues (2003) find some evidence that the growth of expert citations in news coverage is largely reflective of journalists using experts to interpret developments outside of academia, particularly when citing experts from the social sciences. Further, there are other pathologies in the news production process that influence which experts get cited in ways that are unrelated to their source credibility. Most importantly, journalists prefer sources who are reliable and readily available for interviews (Conrad, 1999; Peters, 2008) - traits which are not necessarily correlated with the quality of the expert source. In short, not all coverage of experts in the news media is informative for citizens or normatively desirable. Experts are frequently drawn into coverage to talk about matters 
outside of their expertise, and their opinions - and even their research - may not reflect prevailing opinion among more established and credentialed colleagues.

However, it is normatively desirable to cite experts when they are sending messages in line with prevailing consensus that exists within their respective disciplines. Citizens should be informed of these important areas of agreement in order to take them into account when forming opinions on related issues. Citizens rarely encounter policy experts in their social circles, so the news media play a critical role in informing them of this consensus where it exists (Wilson, 1995). Some experimental literature shows that cues signaling expert consensus are persuasive to citizens (Lewandowsky et al., 2012; van der Linden et al., 2016).

There are strong theoretical grounds to suspect that the mass media routinely fails to provide information on expert consensus even if the overall coverage of experts has, in fact, increased. Technological changes through the 20 th and early 21 st centuries have magnified competition that between media organizations making them more risk-averse and responsive to the tastes of news consumers (Bagdikian, 2004; Shoemaker \& Reese, 2014). This trend has magnified several important regularities in news content. Coverage is likely to be personalized (Bennett, 2007), dramatized (Boykoff \& Boykoff, 2007), and focused on novelty (Wilkins \& Patterson, 1991). The combination of which leads political issues to be framed in ways that are superficial and episodic. News content will typically eschew linkages between stories and continuity in coverage in favour of covering controversial events and personalities (Iyengar, 1991).

One essential piece of context to a policy discussion is the existence of expert agreement or consensus on questions central to that debate. There are a number of important areas of agreement among scientists that are important for policy, like the fact that the climate is warming because of greenhouse gas emissions (Anderegg et al. 2010), or that genetically modified foods are as safe as conventional alternatives (Nicoli et al. 2014). Even more important for matters of public policy are the many areas of agreement among economists, like the destructive impact of trade protectionism or the economic benefits of immigration (Fuller \& Geide-Stevenson, 2003; Whaples, 2009).

Expert consensus may not be prominent in news coverage because consensus, by its very nature, leaves little room for drama and novelty. It requires journalists to use a single angle repeatedly, like the growing threat of global warming (Boykoff \& Boykoff, 2007; Hilgartner \& Bosk, 1988). And discussion related to central questions of public policy is unlikely to find its way into media coverage that is episodic and fragmented rather than thematic and context-rich (Iyengar, 1991). For example, news coverage of trade agreements may focus on the cut and thrust of the 
negotiations and carry claims and counter-claims of activists on either side without setting the context for readers about whether trade is generally welfare enhancing or reducing according to prevailing expert knowledge. An absence of discussion of expert consensus in news content would be troubling, particularly in news stories that are directly relevant to the point of consensus. This motivates the first research question in this paper:

RQ1A: How often do news media use experts as sources to support positions on central questions of policy that have broad expert agreement?

Journalists will also ideally use informative cues, or short-cuts, that signal the existence of consensus. A large literature on cue-taking and heuristics has shown that cues from party elites and interest groups can allow citizens to form beliefs with low levels of information (Lupia, 1994; Mondak, 1993). Expert consensus cues can be persuasive in much the same way (Johnston \& Ballard, 2016; Lewandowsky et al., 2012; van der Linden et al., 2016). These cues are essential in conveying to readers that an expert source is communicating a stance in line with prevailing opinion in the expert community.

RQ1B: How frequently do journalists use clear cues to signal the existence of expert agreement or consensus when appropriate?

Even when expert consensus is features in news content, it is possible that it is not presented in a clear and persuasive manner. One issue is that a journalistic norm of objectivity encourages the equitable presentation of at least two sides of a debate in news stories (Dunwoody, 1999) - often labeled balance. In part, this norm exists because both journalistic and societal beliefs value news for being covered in an even-handed manner (Giannoulis et al., 2010; Schudson, 1978). But it is also a mechanism to protect journalists from attacks that might undermine their credibility (Shoemaker \& Reese, 2014). This practice also furthers journalists' need for personalized and dramatized coverage (Stocking, 1999; Zehr, 2000). However, some journalists - particularly those who specialize in science coverage - may not feel there is any meaningful balance to be had in a story (Allgaier, 2011; Conrad, 1999), while some issues may lend themselves to more pluralized and balanced coverage than others (Rödder and Schäfer, 2010). We cannot take balance as a given in news stories where there are important areas of expert consensus, which leads to my second research question: 
RQ2: To what degree does news coverage provide a balance of perspectives on areas of expert agreement?

Balance as form of bias means that experts in line with the mainstream consensus will often be featured in coverage alongside those that are not representative of the broader expert community often labeled false balance by media critics. Some experimental research has found that exposure to dueling experts can increase public perception of disagreement among experts (Clarke et al., 2015; Koehler, 2016). Falsely balanced coverage of expert consensus may, at times, engender confusion among citizens about the state of expert knowledge and have further, downstream effects on public attitudes.

Notwithstanding research suggesting science journalists cast a skeptical eye on the need for balance (Allgaier, 2011; Conrad, 1999), a number of scholars have argued that false balance was common in media coverage of climate change in the United States where journalists pitted the IPCC consensus against dissenting scientists that often had ties to conservative groups and the fossil fuel industry (Boykoff \& Boykoff, 2004; Zehr, 2000; though for a more skeptical account see Merkley \& Stecula, 2018, and Stecula \& Merkley, 2019). This has also been observed in other areas of sciencebased policy (Dearing, 1995; Dunwoody, 1999; Stocking, 1999). This discussion leads to the second set of research questions pursued here:

RQ3A: How often are contrarian experts presented in coverage alongside those who are in line with the mainstream of the expert community?

The tendency of journalists to dramatize the news means that coverage of a policy area will also be laced with conflict. Taken together with the norm of balance, this means consensus information from experts will often be contested in coverage by polarizing political actors (Bennett, 1990; Merkley \& Stecula, 2018; Trumbo, 1996). We know that citizens often form opinions on political issues by following cues from party elites, ideological organizations, and interest groups (Cohen, 2003; Lupia, 1994; Mondak, 1993). The presence of these actors in political coverage may limit the persuasiveness of experts by priming citizens to resist their messages. 
RQ3B: How often do news media present influential and polarizing information sources that oppose the stated position of the expert community such as parties, interest groups, or ideological organizations?

These three sets of questions motivate much of what follows. However, journalistic practices may also vary across issues, media format, outlet ideology, and even over time. For example, broadcast and cable formats are more conducive to episodic coverage compared to print (Shoemaker \& Reese, 2014). Coverage of relevant expert messages should be less frequent in these media. We know that cable news typically caters to politically engaged audiences (Levendusky, 2013; Prior, 2013) and focus more attention on conflict (Feldman et al., 2012). They might be more likely to situate expert messages in the context of political conflict. Where possible, I draw comparisons related to my research questions across issues and media outlets, and over time.

\section{Data and methods}

It would be exceedingly difficult, if not impossible, to analyze news coverage of all areas of expert agreement that attract media attention. Further, it is not clear what the population of such issues looks like. The best that can be done is to select issues across dimensions that are potentially important. I selected nine issues where there is an important area of expert consensus: the economic effects of immigration, trade protectionism, nuclear power safety, road pricing, vaccine safety and efficacy, GMO safety, Federal Reserve Independence, farm support, and rent control. These issues vary in whether they are related to the natural sciences or economics and in their direction of elite cues. I chose this latter dimension to rule out bias in news coverage of experts that could be driven by partisanship. For example, Republican and conservative elites are typically more hostile to climate change and Federal Reserve independence, while Democratic and liberal elites are more skeptical of the safety of nuclear power and supportive of rent control. Other issues, like trade protectionism and farm support have less clear partisan and ideological divides. These issues also vary in their salience. Issues like immigration and trade protectionism have generated far more news coverage than topics like rent control and the Federal Reserve. I also selected climate change because it has been a dominant focus of science communication literature. More information on the nature of the expert consensus on each issue can be found in Appendix A of the supplementary materials.

I gathered media coverage from the Lexis and LexisNexis Academic services using keywords and subject tags that were selected for coverage rather than precision in order to draw in all possible 
news coverage related to my issues. The keywords and phrases, which are displayed in Appendix B of the supplementary materials, also carefully avoid reference to experts. I selected sources to cover the primary news media (newspaper, newswire, broadcast, and cable), and, where feasible, the ideological spectrum. So I chose the New York Times and the Washington Post as liberal-leaning newspapers, along with USA Today. I also included the Houston Chronicle, the Dallas Morning News, and the San Diego Union-Tribune as a trio of conservative leaning newspapers. ${ }^{2}$ I downloaded transcripts from the three big cable and broadcast networks, along with news content from the Associated Press newswire. For each source, news coverage was gathered as far back in time as was accessible through Lexis and LexisNexis Academic.

My emphasis on over time variation in my sources led me to exclude news sources for media formats that are unavailable until more recent years, like social media and websites. Table B1 in the supplementary materials provides the total number of articles or transcripts across issues. This is by no means a complete picture of the coverage of these issues, but it is a significant and ideologically balanced slice of the news media that covers how the vast majority of Americans receive their news.

In total, I collected nearly 300,000 articles and transcripts. Each of these articles is related in some way to one of the ten issues I am studying. But not all of these articles are especially relevant, in the sense that not all of them speak to the specific area on which experts agree. For example, most immigration stories likely do not focus on the economic effects of immigration, but rather the politics of illegal immigration or refugee flows. Similarly, some climate change coverage may cover the politics of climate mitigation or industry development of alternative energy sources, rather than climate science or climate impacts.

This distinction is important. Journalists may not regard the topics related to pertinent expert consensus as newsworthy, but when a consensus is relevant for a story, cite it where it exists. It would be even more troubling if the citation of expert consensus is low among news stories that are directly relevant to the consensus in question. Consequently, I needed to distinguish these especially

\footnotetext{
${ }^{2}$ The Dallas Morning News and the San Diego Union-Tribune both endorsed Republican presidential candidates in every cycle from 1980 to 2012. The Houston Chronicle endorsed the Republicans in 8 of 9 presidential election cycles. In contrast, the New York Times and Washington Post endorsed Democrats in every cycle in that period, with one exception. Newspaper endorsement histories can be found here: https://noahveltman.com/endorsements/.
} 
relevant articles from the others. However, there were far too many articles for me to manually code, so I trained software to do the coding for me.

Specifically, I made use of RTextTools - an R package that allowed me to train an ensemble of predictive algorithms on a limited sample of manually coded articles. These algorithms learnt how to classify articles from my own coding. I then used these trained algorithms to classify my entire corpus of almost 300,000 articles and transcripts. Supervised machine learning techniques are increasingly used by scholars to study large volumes of text, including news content (Grimmer \& Stewart, 2013; Lacey et al., 2015; Young \& Soroka, 2012).

I manually coded a random sample of 500 articles for each issue as 1 if they contained discussion related to the area of expert agreement for a given issue and 0 if otherwise to train the machine (750 articles were coded for immigration for a total of 5250 articles). I refer to this classification as topic relevance. ${ }^{3}$ The general coding rules are shown in Appendix $\mathrm{C}$ of the supplementary materials. I used a random sample of 400 of these manually coded articles on each issue to train four categorization algorithms in the RTextTools package. The machine classified articles as 1 if three of the four algorithms agreed it was relevant. I then tested the trained algorithms on the remaining 100 manually coded articles for each issue to evaluate the reliability of the machine coding. Accuracy and precision scores were calculated for this evaluation, which are shown in Table D1 in the supplementary materials. ${ }^{4}$ After training the algorithms, they were used to predict the topic relevance of the full corpus of nearly 300,000 news stories. Rates of topic relevance varied considerably across issues, from a low of $2 \%$ for immigration to a high of $58 \%$ of GMOs. These are shown in Table $\mathrm{C} 1$ in the supplementary materials for each issue.

\footnotetext{
${ }^{3}$ Here and throughout a random number generator was used to select samples of news articles from a relevant corpus. An undergraduate research assistant coded a random sample of 200 articles I had classified for relevance. Our coding was in 90\% agreement, with a Krippendorf's Alpha of 0.79. More details on validation can be found in Appendix G in the supplementary materials. ${ }^{4}$ Accuracy tells us how often the algorithm got it right ([True Positives + True Negatives]/Total). But, the purpose of this analysis is to identify a sample of articles for manual coding. As such the more important measure of performance is how many true positives we have relative to all articles that were coded as relevant. This is what the precision score gets us (True Positives/[True Positives + False Positives]). The best estimate for false positives (i.e. precision) in the sample is 10\%.
} 
Next, I built dictionaries of keywords and phrases for each issue using the R package Quanteda. This allowed me to count the number of references to experts in news coverage and to construct a measure that captured the share of coverage with these references. These are referred to as expert citations throughout this paper. On economic issues, the dictionary contained categories for economists and policy analysts, along with a category to capture generic references to experts, featuring words such as analyst, expert, specialist, and professor. On natural science issues, the generic category was maintained, along with categories specific to each issue. These dictionaries, which can be found in Appendix E in the supplementary materials, aimed for coverage rather than precision to set an upper bound on the share of coverage that may contain discussion of the state of expert knowledge on these issues.

The result of my automated analysis is that I am able to identify stories with content relevant to the expert consensus central to each issue - or topic relevance - and the existence of expert citations in any given article. However, this information does not tell us a lot about whether or not expert consensus on an important dimension of a policy issue is being clearly conveyed to readers and viewers. As noted, simply citing an expert in a news story may not be normatively desirable if they are communicating highly contested research or discussing matters outside of their field. So are these citations conveying information related to the expert consensus of interest? Are there clear cues conveying the level of expert agreement? Are expert voices contested by political interests or contrarian experts? These are more nuanced questions that deserve more delicate treatment.

I manually coded a stratified random sample of articles and transcripts that were classified as both relevant and as having an expert citation according to my automated analysis. My aim was to code 100 articles for each relevant subset of sources on each issue. So I coded 100 randomly selected articles each for Republican-leaning newspapers, broadcast sources, liberal cable outlets, and so on. For most issues, particularly those of lower salience and for cable and broadcast coverage, there were not 100 articles or transcripts for a media subset. I coded all articles within that subset in these cases. ${ }^{5}$ Coding criteria can be found in Appendix F in the supplementary materials.

I manually coded the resulting sample of 3,147 articles and transcripts in ways related to my three sets of research questions. At the most superficial level, my automated analysis tells us whether

\footnotetext{
${ }^{5}$ That is, out of a corpus of articles with discussion relevant to the pertinent expert consensus and that had an expert citation, I used a random number generator to identify a sample of 100 articles within each media subset.
} 
or not there is an expert citation in the text of an article. Of articles with these citations only some of them contain a message from, or attributed to, an expert that relates to the area of expert agreement for a given issue even when there is some content in the article that is related to that question. I coded my articles for whether or not any expert citation in the story is linked to a message from an expert related to the consensus for that issue (Present/Absent). I call these expert messages (RQ1A).

Expert messages related to consensus can provide compelling insight into a particular question. On their own, however, they may lead some citizens to wonder whether the stance attributed to the expert reflects their personal view alone or is representative of the broader expert community. After all, there are plenty of areas on which experts are in disagreement. So I coded articles for whether or not the journalist or expert source use a cue that signals to readers or viewers that the expert message is related to some broader agreement in the expert community (Present/Absent). This cue could range in its concreteness from crystal clear statements that indicate there is an expert consensus on the question, to vaguer statements like "experts agree that..." I refer to the subset of expert messages that contain such signals as agreement cues.

I further parsed the agreement cue category. Many of these cues are imprecise in their presentation of the opinion in the broader expert community. A statement like "many experts believe..." or "scientists say..." is not sending a clear statement that there is supermajority or consensus agreement within the expert community on a pertinent question. So I coded agreement cues for whether or not there is such an unambiguous signal of such consensus (Present/Absent). Statements like "most experts say...", "a large majority of economists believe...", or "there is a scientific consensus that..." qualify as a consensus cue. Armed with this coding, I can illustrate the prevalence of each type of expert signal in relevant and total news content on my ten issues, where each finer-grained distinction provides more informative value to citizens on the state of expert knowledge (RQ1B).

I then identified several features related to the entire article that might limit the persuasiveness of expert consensus - balance and conflict. I coded the overall balance of arguments in an article related to positions of expert agreement (-1 to 1). A score of 1 indicates that the relevant information contained in the article is entirely aligned with the position of the mainstream expert community, while -1 means the article is entirely against that position. It was insufficient to simply note alternative perspectives exist on an issue to avoid a -1 score - the journalist had to spend some space paraphrasing opposing arguments or quoting a source in support of the position. I assigned scores of 0.5 and -0.5 if there is a notable emphasis in the article of perspectives in either direction, 
but there is still some evidence of a balancing of perspectives by the journalist. Finally, I gave scores of 0 to indicate that perspectives opposing and supporting the expert consensus position are evenly balanced in an article.

The final two classes of codes only apply to articles in which an expert is cited to communicate a position on an area on which there is substantial expert agreement (i.e. an expert message). Articles were coded 1 for false balance if contrarian experts are cited by journalists to balance the perspective of experts sources who relayed stances aligned with the expert community, and 1 for a polarizing opponent if parties, advocacy organizations, or interest groups are cited in opposition to the position of expert sources that are aligned with the broader expert community.

I trained an undergraduate research assistant to validate my manual coding. ${ }^{6}$ Our coding agreement ranges from $84 \%$ for polarizing opponents to $93 \%$ for balance. These scores do not account for chance agreement, so I calculated Gwet's AC and Krippendorf's Alpha reliability scores as well, the latter of which is very conservative for classification tasks with low base rates, which is the case for several of my measures. The Gwet's AC scores ranges from 0.69 in the case of polarizing opponents to 0.81 for expert messages, while the Krippendorf's Alpha ranges from 0.60 for false balance to 0.73 for balance. ${ }^{7}$

\section{Results}

The main takeaway finding is that expert messages related to areas of consensus and clear cues signaling that consensus are simply not that common in news content. A minority of relevant

\footnotetext{
${ }^{6}$ The research assistant was given a coding manual that was developed iteratively over the course of four practice rounds where I evaluated their coding quality and provided feedback. The final coding manual is shown in Appendix $\mathrm{F}$ in the supplementary materials. After the training, they coded 250 additional articles, which were then used to inform the intercoder reliability scores.

${ }^{7}$ These scores can be evaluated based on whether the cumulative probability of being in a category or higher is greater than 0.9 , which is, in part, dependent on the standard errors. Our percentage agreement scores are all rate as “very good” according to Altman's (1991) benchmarking scale (0.8 to 1) recommended by Gwet (2014). Our Gwet's AC scores all rate as "good” (0.6 to 0.8). Our Krippendorf's Alpha scores all rate as "good" as well, with the exception of false balance, which is rated as "moderate" (with a score of 0.6 , benchmark of 0.4 to 0.6 ). The low score on false balance for the Krippendorf's Alpha is in large part due to the infrequency of false balance in our sample. More details on the validation tests can be found in Appendix G in the supplementary materials.
} 
news stories have an expert citation captured by the automated dictionary analysis (44\%). This is a relatively high number, but not all of these articles contain discussion related to the consensus in question. In fact only half of articles with expert citations have a clear message related to an area of expert agreement based on my hand coding (23\%), while only a fraction of these articles contain a signal of agreement within the expert community $(9 \%)$ and far fewer explicitly state there is majority or consensus agreement $(3 \%)$. Messages from experts signaling information related to an area of agreement are infrequent, while cues indicating the existence of expert agreement or consensus are rarer still. The news media does not often cover expert consensus where it exists even in news articles that contain discussion directly relevant to that consensus. (RQ1A \& RQ1B).
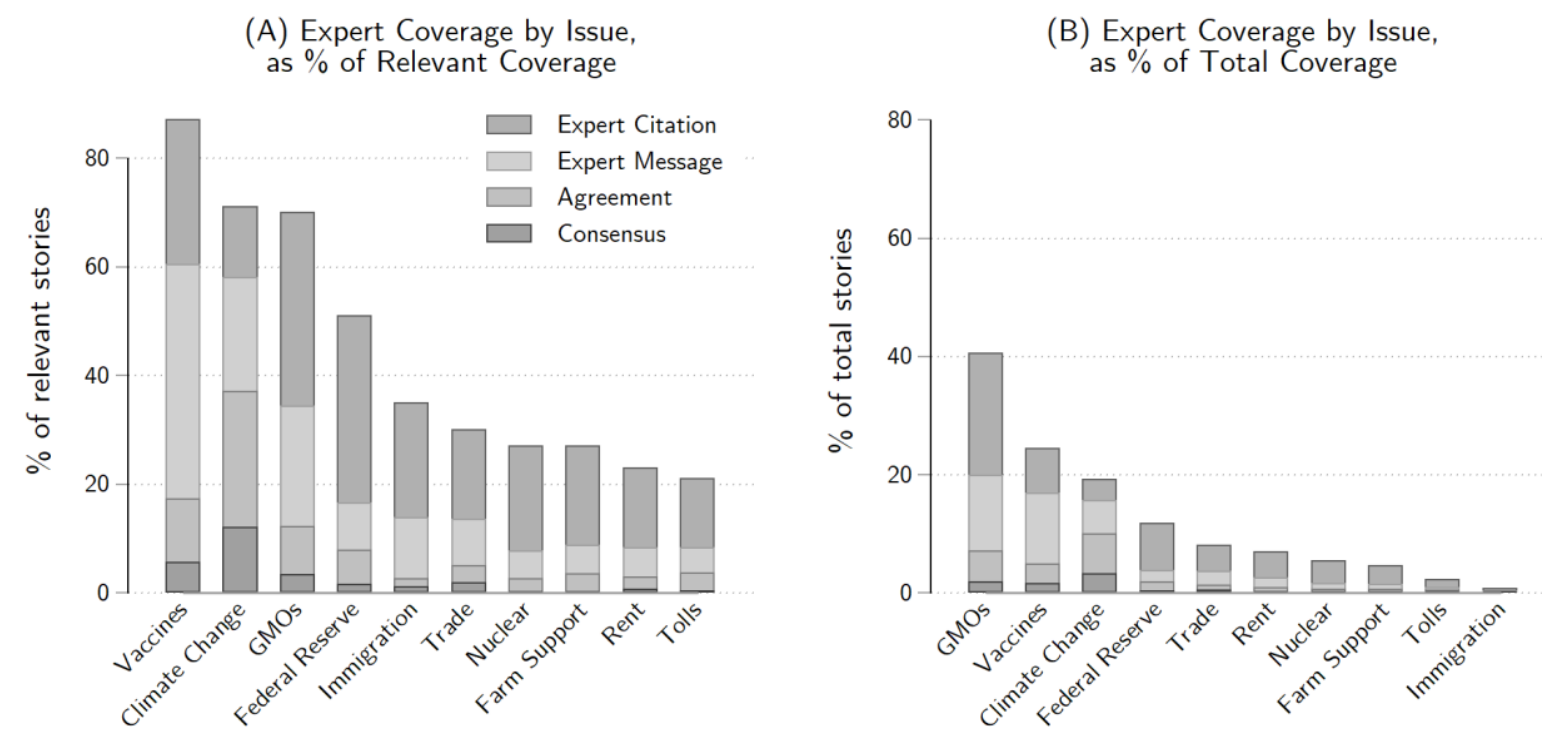

Figure 1. Prevalence of expert citations, messages, and cues in news coverage. (A) As a share of relevant coverage (i.e. coded " 1 " by the trained classification algorithms). (B) As a share of total coverage downloaded from Lexis and LexisNexis Academic using keywords and subject tags. Note: Expert citation means the automated dictionary picked up a reference to an expert in a news story, while expert message means the hand coding revealed a message in an article by an expert that was relevant to a position of expert agreement.

There is notable variation across issues in the presentation of expert messages. Panel A of Figure 1 presents the number of expert citations, messages, and cues expressed as a share of relevant news coverage across each of the issues in this study. The story is modestly more positive in vaccine $(87 \%, 60 \%, 17 \%$, and $6 \%)$ and climate change coverage $(71 \%, 58 \%, 37 \%$, and $12 \%)$. However, agreement cues only exceed $10 \%$ of coverage on these two issues and GMOs (12\%). Agreement and consensus cues are only robustly used in climate change coverage. 
Most of my sample of news articles, however, do not contain discussion relevant to the expert consensus in question. Panel B of Figure 1 displays the prevalence of expert citations, messages, and cues, expressed as a share of the total volume of coverage gathered from Lexis and LexisNexis Academic using a variety of keywords and subjects tags indicating relevance for a policy area. Only a small minority of stories contain both an expert citation and content relevant to the consensus in the expert community $(12 \%$ of the total). Of these, only a little over half contain messages from experts that speak to the area of agreement ( $7 \%$ of the total), only a quarter have a cue that signals expert agreement (3\% of the total), and 1 in 15 have a clear consensus cue $(0.8 \%$ of the total). Of course, we cannot expect journalists to cite expert consensus in news stories that lack content relevant to the consensus. But this provides a useful illustration of the fact that information related to expert consensus is contained in an extremely small portion of a news consumer's media diet on these issues.

(A) Expert Coverage Over Time

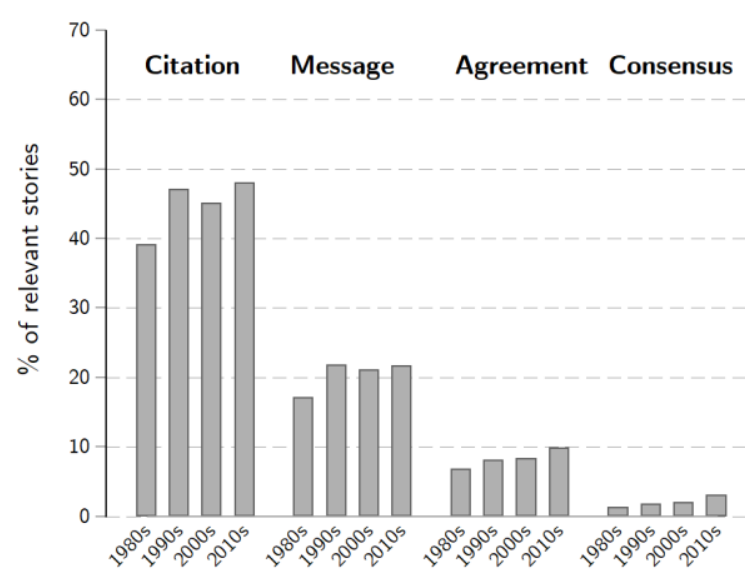

(B) Expert Coverage by Media Format

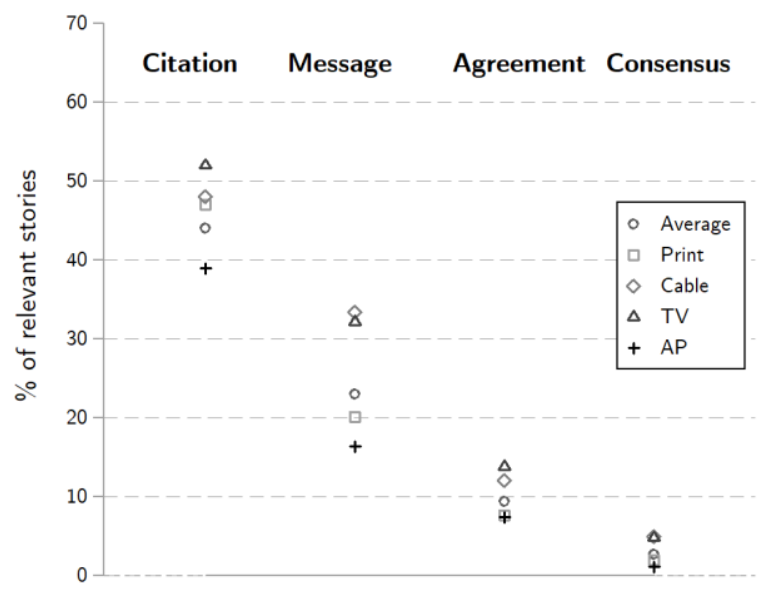

Figure 2. Share of relevant coverage with expert citations, messages, and cues. (A) Comparisons over time. (B) Comparisons by media format. Average represented by the circle. Note: All results expressed as a share of relevant news coverage (i.e. coded "1" by the trained classification algorithms).

Panel A of Figure 2 presents the share of expert citations, messages, and cues over time. The results here are expressed as a share of content that the machine classified as relevant. It shows that the tendency of journalists to cite experts has gone up since the $1980 \mathrm{~s}$, rising from $39 \%$ of relevant coverage to $48 \%$ after 2010. This is in line with findings by Albæk and colleagues (2003) in the Danish context. Likewise, coverage of expert messages related to areas of consensus has increased, 
but more modestly from $17 \%$ in the 1980 s to $22 \%$ after 2010 . Agreement and consensus have also slightly increased from 7 to $10 \%$ for the former and from 1 to $3 \%$ for the latter. There are important differences in this regard across issues, however. In the natural sciences, journalists appear to increasingly use agreement and consensus cues. For example, agreement cues have increased in coverage of nuclear power (2\% to $6 \%$ ), vaccines ( $9 \%$ to $23 \%)$, and GMOs $(10 \%$ in the 1990 s to $21 \%$ after 2010 ), while consensus cues have become more common in climate change ( $8 \%$ to $15 \%)$, vaccine ( $0 \%$ to $9 \%$ ), and GMO coverage (3\% in the 1990 s to $8 \%$ after 2010$)$. The results displaying differences across issues and over time can be found in Table H1 in the supplementary materials.

Panel B of Figure 2 presents the share of expert citations, messages, and cues across different media formats for all issues combined. The AP newswire cites experts less frequently than other formats $(39 \%)$. The share of relevant coverage with expert messages on an area of agreement is higher in cable (33\%) and broadcast news (32\%). All media formats are unlikely to provide agreement or consensus cues, but they are again comparatively more common in cable (12 and 5\%) and broadcast (14 and 5\%), compared to print ( 8 and $2 \%) .{ }^{8}$ It is worth noting, however, that these formats contained far less content relevant to areas of expert agreement at the outset.

\section{Balance and polarizing conflict in news coverage of experts}

There is one area where the media at least partially defy pessimistic expectations: balance (RQ2). To be sure, most articles displayed some balance of perspectives in favour and opposed to the stance of the expert community, but emphasis in either direction could be detected in around $80 \%$ of news stories. Journalists typically orient their coverage in favor of the position of the mainstream expert community. 56\% of articles emphasize arguments that support the expert position compared to $23 \%$ that emphasize arguments opposed to areas of expert agreement across the issues used here.

The balance score I use here ranges from -1, where all arguments used in the news story reject the expert position, to 1, where all arguments support the expert position. 0 means that, on average, coverage is evenly balanced between positions in support of and opposed to the expert position.

\footnotetext{
${ }^{8}$ Republican-leaning outlets (e.g. Fox News) were less likely than Democratic-leaning outlets (e.g. $C N N)$ to feature expert citations or messages on issues where Republican and conservative elites resist expert consensus. The reverse is true on issues where Democratic-elites resist expert consensus. Results displayed in panel A of Figure H1 of the supplementary materials.
} 
The media scored 0.3 on this measure, averaged across format and all issues, indicating a modest orientation towards expert consensus positions in relevant news coverage.

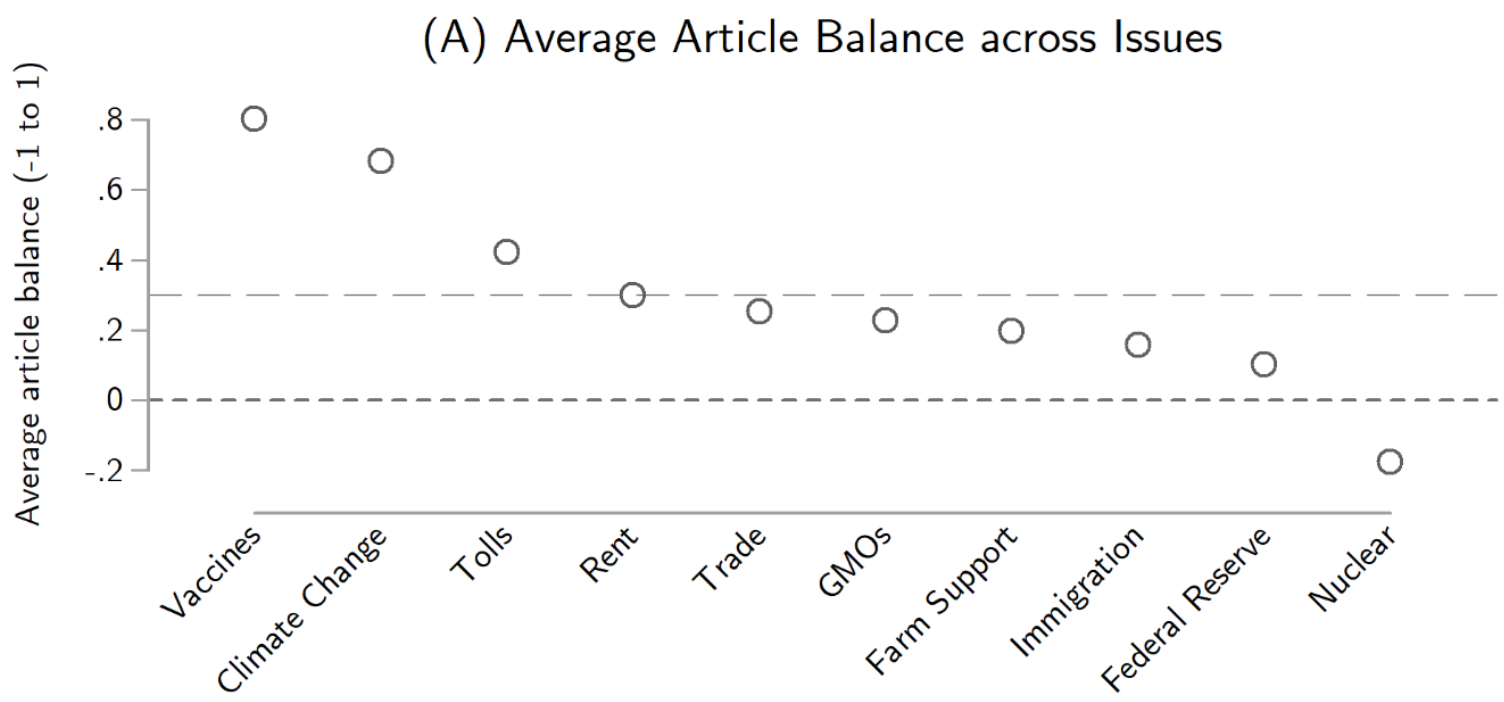

(B) Balance Over Time

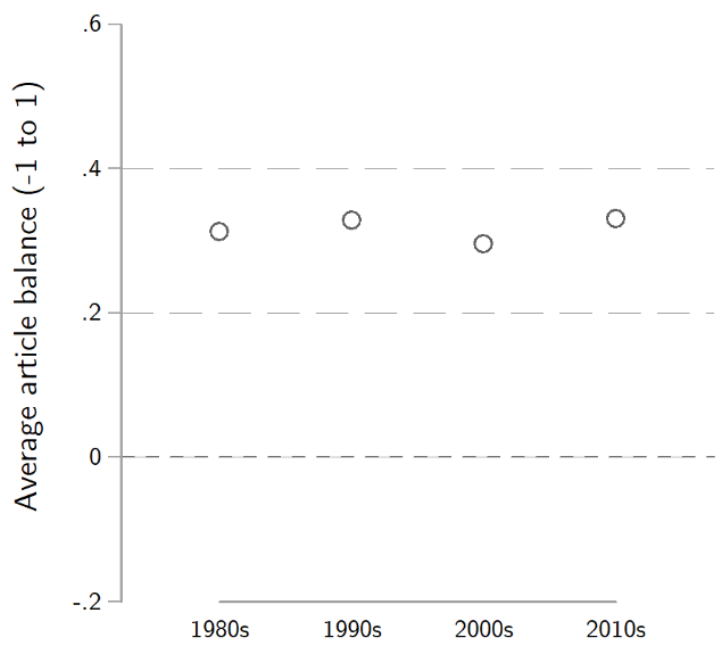

(C) Balance across Media Format

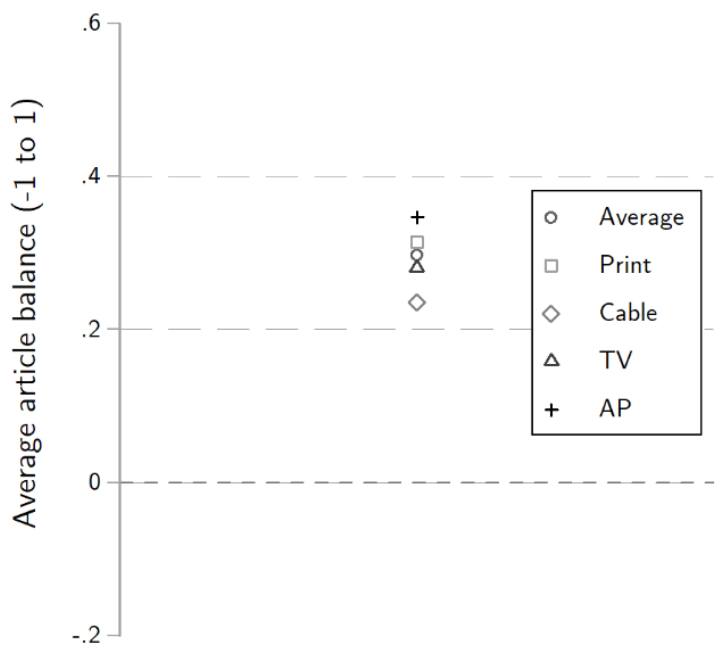

Figure 3. Average article balance in relevant news content with expert references. (A) Comparisons by issue. Dashed line represents the average. (B) Comparisons over time. (C) Comparisons by media format. Average of all media types represented by the circle. Solid line at 0 represents balanced coverage, on average. Note: Scale runs from -1, where all arguments in the news story reject the expert position, to 1, where all arguments support the expert position. 0 represents a relatively equal balance of perspectives. 
Panel A of Figure 3 displays the average balance score for news stories across issues, where the dashed line indicates the average across all of these issues. Climate change and vaccine coverage appear to be the most reflective of mainstream expert positions (0.68 and 0.80). The climate change score rises to 0.87 when excluding Fox News, whose coverage of climate change is unsurprisingly oriented against the expert consensus (-0.17). In contrast, nuclear power coverage leans modestly against the position of the expert community $(-0.18)$. There is no clear dividing line between issues of natural science and economics on this dimension. The safety of GMOs and nuclear power are far more contested in news coverage than climate change or the safety and efficacy of vaccines.

Panel B of Figure C shows that balance has been steady over time. This average masks some heterogeneity across issues. News coverage increasingly emphasizes arguments supporting positions of expert consensus on the economic effects of immigration, rising from -0.06 in the 1980 s to 0.34 after 2010. The same is true in news content on the safety of GMOs (0.19 in the 1990 s to 0.35 after 2010), and federal farm support (0.05 to 0.61). In contrast, both road toll (0.69 in the 1990 s to 0.09 after 2010) and rent control news content (0.37 in the 1980 s to 0.09 after 2000$)$ increasingly emphasize arguments opposed to expert consensus.

Climate change news coverage, for its part, shows movement away from the position of expert consensus, falling from 0.76 in the 1980 s to 0.64 after 2000 , but this change is an artifact of Fox News's entry into the sample. Without Fox, climate change content has moved towards the position of expert consensus, rising from 0.76 in the 1980 s to 0.86 after 2000 . The full results can be found in Table H2 of the supplementary materials. Panel C of Figure 3 shows that balance is more common in cable news, as we would expect $(0.23){ }^{9}$

How likely are journalists to engage in much maligned false balance by citing contrarian expert sources (RQ3A)? It turns out that this is not standard practice. False balance only occurs in 21\% of coverage where expert messages are featured, averaged across media format and all issues. Panel A of Figure 4 shows that the prevalence of false balance is notably higher than the average on three issues: GMOs (40\%), nuclear safety (38\%), and immigration (33\%), while rates of false balance in climate change and vaccine coverage are below the average represented by the dashed line in the

\footnotetext{
${ }^{9}$ Democratic-leaning outlets are more likely than Republican-leaning outlets to emphasize arguments aligned with the expert consensus on issues where Republican and conservative elites resist expert consensus. The reverse is true on issues where Democratic-elites resist expert consensus. Results displayed in panel B of Figure H1 in the supplementary materials.
} 
figure. The contrast between the relatively high rates of false balance in GMO coverage and low rates in climate change $(19 \%)$ and vaccine coverage $(13 \%)$ are striking given the fact that most scholarly attention has focused on the latter two issues.

(A) Prevalence of False Balance by Issue

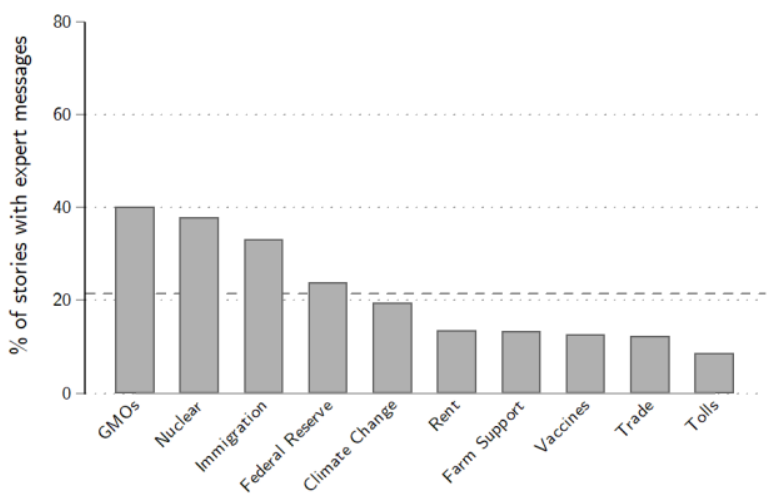

(C) Prevalence of False Balance \& Polarizing Sources Over Time

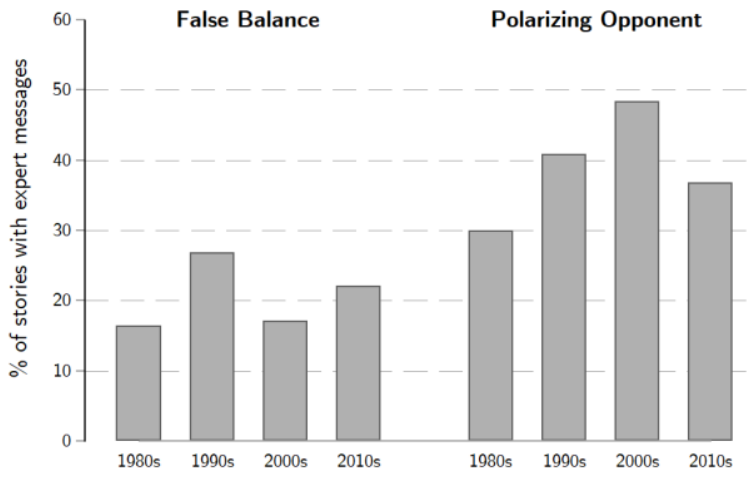

(B) Prevalence of Polarizing Opponents by Issue

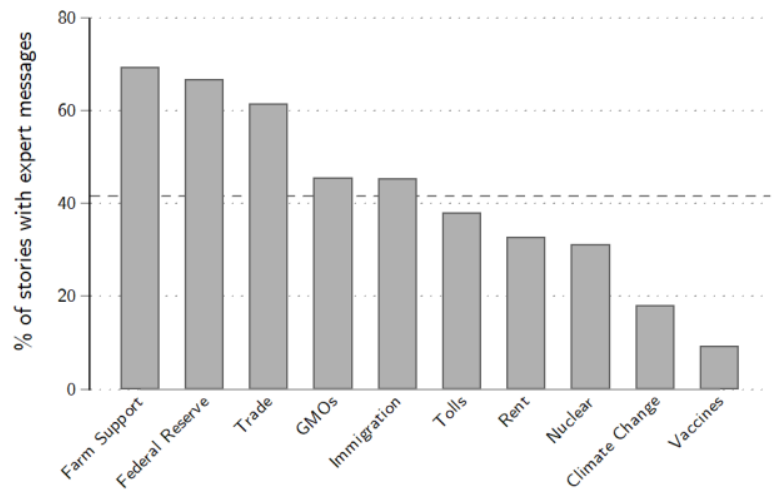

(D) Prevalence of False Balance \& Polarizing Sources by Media Format

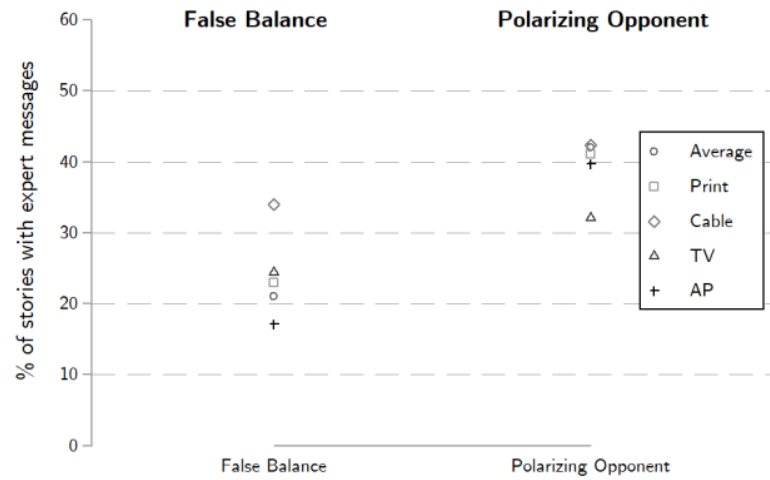

Figure 4. False balance and polarizing opponents in relevant news content with expert messages. (A) Prevalence of false balance by issue. Dashed line represents the average. (B) Prevalence of polarizing opponents by issue. Dashed line represents average. (C) Comparisons over time. (D) Comparisons by media format. Average across media types represented by the circle. Note: All results expressed as a share of coverage with a message from an expert related to an area of expert consensus.

Panel B of Figure 4 shows that the practice of false balance has remained steady over time. There is, however, variation across issues. False balance has decreased in climate change coverage from $28 \%$ in the 1980 s to $10 \%$ after 2010 , and in news content on the economic effects of immigration, falling from $54 \%$ in the 1990 s to only $14 \%$ after 2010 . False balance has also decreased from $50 \%$ in the 1980 s to $27 \%$ after 2010 in coverage of nuclear power. The full results can be 
found in Table $\mathrm{H} 2$ of the supplementary materials. Panel $\mathrm{C}$ of Figure 4 plots the share of coverage with expert messages characterized by false balance across media format. The prevalence of false balance is notably higher in cable news (34\%).

It is comparatively more common for journalists to satisfy their norm of balance by citing political actors opposed to the expert position (RQ3B). 42\% of news stories with expert messages also have polarizing opponents, averaged across media format and all issues. Panel B of Figure 4 plots the substantial variation that exists across issues on this dimension with the average indicated by the dashed line. The citation of polarizing opponents is typically more common for economic issues like farm support (69\%), Federal Reserve independence (67\%), and trade (62\%), while it is less common in articles about climate change $(18 \%)$ and vaccines $(9 \%)$. There is a clear divide between economic and science issues, with the former more frequently citing polarizing opponents.

Panel $\mathrm{C}$ shows that there has been an increase in the citation of polarizing opponents from $30 \%$ in the 1980 s to $48 \%$ in 2000 . These actors have raised their profile more readily in news coverage related to rent control (31\% to 50\%) and road tolls (12\% in the 1980 s to $38 \%$ after 2010$)$. In contrast, polarizing opponents have been cited less in coverage of free trade $(71 \%$ in the 1980 s to $33 \%$ after 2010). These results can be found in Table H2 of the supplementary materials. Panel D of Figure 5 shows that the citation of polarizing opponents is comparatively more common in cable news $(42 \%)$, but differences are quite modest. ${ }^{10}$

\section{Discussion}

The use of experts as news sources by journalists is not inherently desirable in all circumstances. Oftentimes experts are drawn into stories to talk about matters outside of their fields of expertise or to provide highly contested points of view (Albæk et al. 2003). However, the communication of expert consensus can be valuable for citizens in many different policy domains. And yet we see that aggregate public opinion is often at odds with such consensus on a wide variety of issues. Most research emphasizes the fact that segments of the public are often motivated to resist consensus messages when they conflict with their values and ideologies. Motivated skepticism is, to be sure, part of the problem, particularly on salient issues like climate change. But neglected in this narrative is the political information environment - the information space used by citizens to learn

\footnotetext{
${ }^{10}$ There is evidence of partisan or ideological bias across outlets in the prevalence of false balance and polarizing opponents. Results displayed in panel C of Figure H1 in the supplementary materials.
} 
about political issues. Lacking policy specialists in their social circles, most citizens learn about complex issues from the news media - the most central set of actors in the political information environment. However, journalists are typically resistant to covering relevant context to political debates that are lacking in drama and novelty - much like expert consensus. The lack of congruence between experts and the public may, in part, be an information problem on many policy issues.

Journalists cannot be expected to cover expert consensus when it is not relevant for their coverage of day-to-day political events and controversies. However, the most significant finding in the data presented above is how unusual it is for media to present information about expert consensus even when it is directly relevant for a news story. Out of all stories about issues like climate change, immigration, and international trade that have some discussion relevant to an area of expert consensus, only as small minority have a message from experts aligned with the consensus (23\%). Only a minority of these stories have some signal of expert agreement $(9 \%)$ and even fewer contain a strong signal of consensus (3\%). Expert messages related to areas of consensus are relatively more common in vaccine and climate change coverage, with agreement and consensus cues appearing primarily in the former, but even still the overall numbers are not that impressive (RQ1A and B). If experts have become prevalent in news coverage, it does not appear to be the case that this has carried over into signals of expert consensus, possibly because much of this increase has involved journalists using experts for political commentary unrelated to academic research (Albæk et al. 2003).

When journalists do cover expert consensus, this signal is not clouded by balance as much as we might expect (RQ2). On the whole, journalists place considerable emphasis on arguments supportive of the expert perspective ( 0.30 on the -1 to 1 scale of balance). There is no doubt that a norm of balance operates to a degree, as most articles provide some effort to illustrate arguments for and against positions of expert agreement, but it would be a mistake to then assume that most articles contain an equal balance of perspectives. Only a minority of stories have an approximation of balance on these issues (20\%).

Again, there is some meaningful variance across issues. In particular, coverage of climate change (0.84, Fox News excluded) and childhood vaccinations (0.80) stand out for having coverage that strongly emphasizes positions of expert agreement and that largely ignore critics. Balanced and oppositional coverage of climate change is primarily confined to the conservative media echo chamber - represented here by Fox News (-0.13). Any impression that the media provides truly balanced coverage on issues involving agreement among expert communities is mistaken and this is especially true for climate change and vaccines. 
And what actors are cited in opposition to mainstream, expert communities? Surprisingly, instances of false balance between experts and contrarian specialists are relatively uncommon (RQ3A, $21 \%$ ), at least compared to the citation of opposing polarizing actors (RQ3B, 42\%). The former number is higher for natural science issues, but this is driven primarily by levels of false balance in coverage of GMO safety (40\%) and nuclear power (38\%), rather than climate change $(19 \%)$ and vaccines $(13 \%)$. Although most scholarly work on false balance has emphasized its prevalence in climate change coverage, it appears that this issue is much more salient on other issues like GMOs. More often than not the media balance expert perspectives against those of political actors (RQ3B) rather than other experts (RQ3A), and this is especially true on economic issues. This speaks to Allgaier's (2011) finding that science journalists are less likely to provide pluralized, contested coverage involving experts. Although, importantly, we see less of a clear divide between natural science and economic issues when it comes to the citation of contrarian experts.

Taken together, there are some important implications for future research and for efforts at science communication. Perhaps most importantly, they suggest we need to take seriously the environment in which citizens learn about political issues, and specifically the news coverage to which they are exposed. More often than not information on expert consensus does not find its way into episodic, event-focused news content. Although it is true that processes of motivated reasoning often block counter-attitudinal signals from experts, this is not universally the case. Scholars have shown that consensus cues from scientists can be persuasive even on a highly polarized issues like climate change (Lewandowsky et al. 2012; van der Linden et al., 2016). Journalists have done a fair job conveying the existence of expert consensus on climate change - a practice that has not been mirrored on other issues even when coverage is directly relevant to the expert consensus in question. Journalists need to extend this practice into other domains. Expert communities, for their part, need to do a better job in martialling consensus documents, as has been done on climate change, to allow journalists to more easily identify what points have widespread agreement among relevant experts and which do not.

There is a lesson for scholars as well. We need to be attentive to the way information from experts is typically communicated in the real world. More often than not we use stylized experiments for insight on how certain messages, such as those from experts, influence behaviour. However, this information never exists in isolation. More often than not expert messages are found alongside messages from polarizing information sources. It is not obvious that anything can or should be done to change journalistic practice on this front. Expert messages have relevance for policy debates, so 
parties, interest groups, and advocacy organizations will inevitably receive coverage and deserve to have their voices heard. We need a stronger understanding of the implications of this politicization on persuasion via expert consensus messaging. Are consensus cues persuasive in this context? If not, are there alternative ways of conveying messages of expert consensus that can be effective?

There are often large, problematic gaps between expert and public opinion across a range of issues. In order to fully understand why they exist, scholars need to take the political information environment seriously and design experimental treatments rooted in such analyses. Only then can journalists, educators, science communicators, analysts, and policymakers advance an agenda that can effectively address the problem.

\section{References}

Albæk, E., Christiansen, P. M., Togeby, L. (2003). Experts in the mass media: Researchers as sources in Danish Daily Newspapers, 1961-2001. Journalism and Mass Communication Quarterly, 80(4), 937-948.

Albæk, E. (2011). The interaction between experts and journalists in news journalism. Journalism, 12(3), 335-348.

Allgaier, J. (2011). Who is having a voice? Journalists' selection of sources in a creationism controversy in the UK press. Cultural Studies of Science Education, 6, 445-467.

Altman, D. G. (1991). Practical statistics for medical research. London: Chapman \& Hall.

Anderegg, W. R., Prall, J. W., Harold, J., Schneider, S. H. (2010). Expert credibility in climate change. Proceedings of the National Academy of Sciences, 107(27), 12107-12109.

Bagdikian, B. (2004). The new media monopoly. Boston: Beacon Press.

Bennett, W. L. (1990). Toward a theory of press-state relations. Journal of Communication, 40(2), 103125.

Bennett, W. L. (2007). News: The politics of illusion, 2nd edition. New York: Pearson Longman.

Boykoff, M. T., \& Boykoff, J. M. (2004). Balance as bias: Global warming and the US prestige press. Global Environmental Change, 14(2), 125-136.

Boykoff, M. T., \& Boykoff, J. M. (2007). Climate change and journalistic norms: A case-study of US mass-media coverage. Geoforum, 38(6), 1190-1204.

Clarke, C. E., Dixon, G. N., Holton, A., \& McKeever, B. W. (2015). Including 'evidentiary balance' in news media coverage of vaccine risk. Health Communication, 30(5), 461-472. 
Cohen, G. L. (2003). Party over policy: The dominating impact of group influence on political beliefs. Journal of Personality and Social Psychology, 85(5), 808-822.

Conrad, P. (1999). Uses of expertise: Sources, quotes, and voice in reporting of genetics in the news. Public Understanding of Science, 8, 285-302.

Dearing, J. W. (1995). Newspaper coverage of maverick science: Creating controversy through balancing. Public Understanding of Science, 4(4), 341-361.

Dunwoody, S. (1999). Scientists, journalists, and the meaning of uncertainty. In S. M. Friedman, S. Dunwoody, \& C. L. Rogers (Eds.), Communicating uncertainty: Media coverage of new and controversial science (pp. 59-80). Mahwah, NJ: Lawrence Erlbaum.

Feldman, L., Maibach, E. W., Roser-Renouf, C., \& Leiserowitz, A. (2011). Climate on cable: The nature and impact of global warming coverage on Fox News, CNN, and MSNBC. International Journal of Press/Politics, 17(1): 3-31.

Fuller, D, \& Geide-Stevenson, D. (2003). Consensus among economists: Revisited. The Journal of Economic Education, 34(4), 369-387.

Giannoulis, C., Botetzagias, I., \& Skanavis, C. (2010). Newspaper reporters' priorities and beliefs about environmental journalism: An application of Q-methodology. Science Communication, 32(4), 425-466.

Gwet, K. L. (2014). Handbook of inter-rater reliability: The definitive guide to measuring the extent of agreement among raters, $4^{\text {th }}$ edition. Gaithersburg, MD: Advanced Analytics.

Hilgartner, S., \& Bosk, C. L. (1988). The rise and fall of social problems: A public arenas model. American Journal of Sociology, 94(1). 53-78.

Iyengar, S. (1991). Is anyone responsible? How television frames political issues. Chicago, IL: University of Chicago Press.

Johnston, C. D., \& Ballard, A. O. (2016). Economists and public opinion: Expert consensus and economic policy judgments. Journal of Politics, 78(2), 443-456.

Kahan, D. M., Jenkins-Smith, H., \& Braman, D. (2012). Cultural cognition of scientific consensus. Journal of Risk Research, 14, 147-174.

Koehler, Derek J. 2016. Can journalistic 'false balance' distort public perception of consensus in expert opinion? Journal of Experimental Psychology: Applied, 22(1), 24-38.

Levendusky, M. (2013). How partisan media polarize America. Chicago: The University of Chicago Press. 
Lewandowsky, S., \& Oberauer, K. (2016). Motivated rejection of science. Current Directions in Psychological Science, 25(4), 217-222.

Lewandowsky S., Gilles E. G., Vaughan, S. (2012). The pivotal role of perceived scientific consensus in acceptance of science. Nature Climate Change, 3, 399-404.

Lupia, A. (1994). Shortcuts versus encyclopedias: Information and voting behavior in California insurance reform elections. American Political Science Review, 88, 63-76.

Merkley, E., \& Stecula, D. A. (2018). Party elites or manufactured doubt? The informational context of climate change polarization. Science Communication, 40(2), 258-274.

Mondak, J. J. (1993). Public opinion and heuristic processing of source cues. Political Behavior, 15(2), 167-192.

Nicolia, A., Manzo, A., Veronesi, F., \& Rosellini, D. (2014). An overview of th4e last 10 years of genetically engineered crop safety research. Critical Reviews in Biotechnology, 34(1), 77-88.

Peters, H. P. (2008). Scientists as public experts. In M. Bucchi \& B. Trench (Eds.), Handbook of public communication of science and technology (pp. 131-146). London and New York: Routledge.

Pew Research Center. (2015). Public and scientists' views on science and society.

http://assets.pewresearch.org/wpcontent/uploads/sites/14/2015/01/PI ScienceandSociety Report 012915.pdf

Prior, M. (2013). Media and political polarization. Annual Review of Political Science, 16(1), 101-127.

Rödder, S., \& Schäfer, M. S. (2010). Repercussion and resistance: An empirical study on the interrelation between science and the mass media. Communications, 35, 249-267.

Sapienza, P., \& Zingales, L. (2013). Economic experts versus average Americans. American Economic Review, 103(3), 636-642

Schudson, M. (1978). Discovering the news. New York: Basic Books.

Shoemaker, P. J., \& Reese, S. D. (2014). Mediating the message in the $21^{\text {st }}$ century: A media sociology perspective. New York: Routledge.

Steele, J. E. (1990). Sound bite seeks expert. Washington Journalism Review, September, 28-29.

Stocking, S. H. (1999). How journalists deal with scientific uncertainty. In S. M. Friedman, S. Dunwoody, \& C. L. Rogers (Eds.), Communicating uncertainty: Media coverage of new and controversial science (pp. 23-42). Mahwah, NJ: Lawrence Erlbaum.

Trumbo, C. (1996). Constructing climate change: Claims and frames in U. S. news coverage of an environmental issue. Public Understanding of Science, 5(3), 269-283. 
Van der Linden, S. L., Leiserowitz, A. A., Feinberg, G. D., \& Maibach, E. W. (2015). The scientific consensus on climate change as a gateway belief: Experimental evidence. PLoS One, 10(2), e0118489.

Whaples, R. (2009). The policy views of American Economic Association members: The results of a new survey. Economic Journal Watch, 6(3), 337-348.

Wilkins, L., \& Patterson, P. (1991). Risky business: Communicating issues of science, risk, and public policy. New York: Greenwood Press.

Wilson, K. M. (1995). Mass media as sources of global warming knowledge. Mass Communications Review, 22(1-2), 75-89.

Zehr, S. C. (2000). Public representations of scientific uncertainty about global climate change. Public Understanding of Science, 9(2), 85-103. 